\title{
Arenicolins: $\boldsymbol{C}$-Glycosylated Depsides from Penicillium arenicola
}

\author{
Bruno Perlatti, ${ }^{\dagger}$ Nan Lan,$\nmid$ Cody E. Earp,+ Solmaz AghaAmiri, ${ }^{\S}$ Servando Hernandez Vargas,$\S$ \\ Ali Azhdarinia, ${ }^{\S}$ Gerald F. Bills, ${ }^{\dagger}$ James B. Gloer ${ }^{*},+$
}

†Texas Therapeutic Institute, The Brown Foundation Institute of Molecular Medicine, University

of Texas Health Science Center at Houston, Houston, Texas 77054, United States

Department of Chemistry, University of Iowa, Iowa City, Iowa 52242, United States

$\S$ The Brown Foundation Institute of Molecular Medicine, McGovern Medical School, University of Texas Health Science Center at Houston, Houston, Texas 77054, United States

\section{List of Supporting Information}

Figure S1. a) ESI ${ }^{+} \mathrm{MS}$ of arenicolin A (1); b) ESI-MS of arenicolin A (1); c) ESI ${ }^{+} \mathrm{MS}$ of arenicolin B (2); d) ESI-MS of arenicolin B (2); e) ESI- HRMS of arenicolin A (1); f) ESIHRMS of arenicolin B (2); g) Fragment ions observed in ESI--MS for arenicolins A (and B). Figure S2. ${ }^{1} \mathrm{H}$ NMR spectrum of arenicolin $\mathrm{A}(\mathbf{1})$ in $\mathrm{CD}_{3} \mathrm{OD}$. $(500 \mathrm{MHz})$

Figure S3. ${ }^{13} \mathrm{C}$ NMR spectrum of arenicolin $\mathrm{A}(\mathbf{1})$ in $\mathrm{CD}_{3} \mathrm{OD}$. (125 MHz)

Figure S4. HSQC spectrum of arenicolin $\mathrm{A}(\mathbf{1})$ in $\mathrm{CD}_{3} \mathrm{OD}$.

Figure S5. COSY spectrum of arenicolin $\mathrm{A}(1)$ in $\mathrm{CD}_{3} \mathrm{OD}$.

Figure S6. $\mathrm{HMBC}$ spectrum of arenicolin $\mathrm{A}(\mathbf{1})$ in $\mathrm{CD}_{3} \mathrm{OD}$.

Figure S7. NOESY spectrum of arenicolin $\mathrm{A}(\mathbf{1})$ in $\mathrm{CD}_{3} \mathrm{OD}$.

Figure S8. ${ }^{1} \mathrm{H}$ NMR spectrum of arenicolin $\mathrm{B}(2)$ in $\mathrm{CD}_{3} \mathrm{OD}$. (500 MHz)

Figure S9. ${ }^{13} \mathrm{C}$ NMR spectrum of arenicolin $\mathrm{B}(2)$ in $\mathrm{CD}_{3} \mathrm{OD}$. (125 MHz)

Figure S10. COSY spectrum of arenicolin $\mathrm{B}(2)$ in $\mathrm{CD}_{3} \mathrm{OD}$.

Figure S11. HSQC spectrum of arenicolin $\mathrm{B}(2)$ in $\mathrm{CD}_{3} \mathrm{OD}$.

Figure S12. $\mathrm{HMBC}$ spectrum of arenicolin $\mathrm{B}(2)$ in $\mathrm{CD}_{3} \mathrm{OD}$.

Figure S13. ${ }^{1} \mathrm{H}$ NMR spectrum of arenicolin $\mathrm{B}(2)$ in $\mathrm{CD}_{3} \mathrm{OD} / \mathrm{Na}_{2} \mathrm{CO}_{3}(500 \mathrm{MHz})$

Figure S14. Aromatic region of the ${ }^{1} \mathrm{H}$ NMR spectrum of arenicolin B (2) under different conditions.

Figure S15. ECD spectrum of arenicolin A (1) in $\mathrm{MeOH}$.

Figure S16. ECD spectrum of arenicolin B (2) in $\mathrm{MeOH}$. 

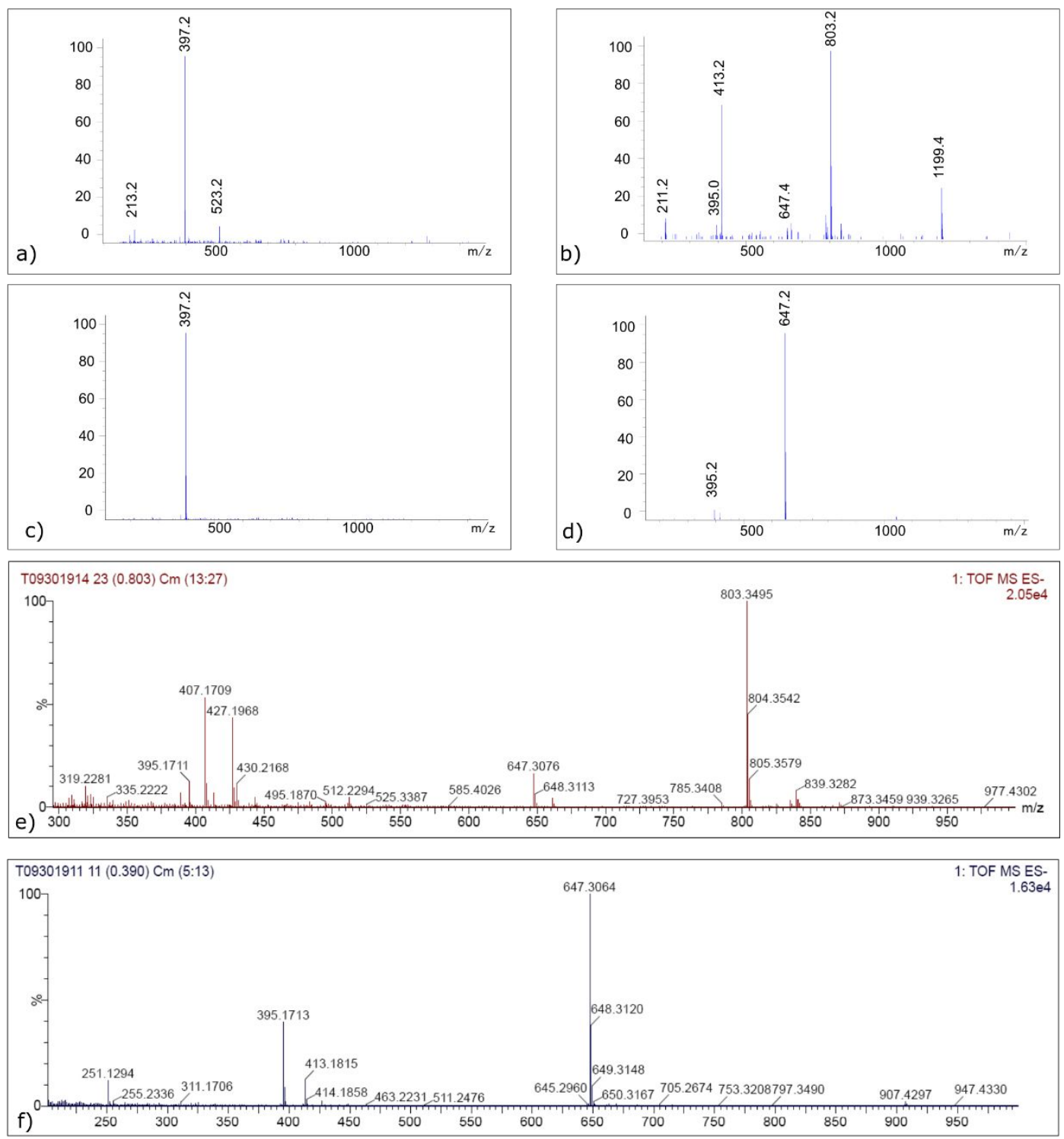

g)

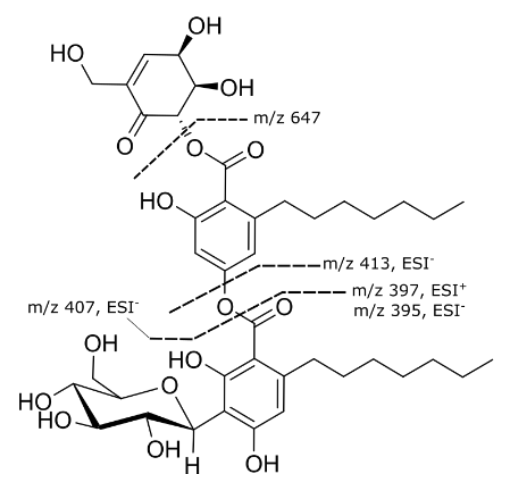

Figure S1. a) ESI ${ }^{+} \mathrm{MS}$ of arenicolin A (1); b) ESI-MS of arenicolin A (1); c) ESI ${ }^{+} \mathrm{MS}$ of arenicolin B (2); d) ESI-MS of arenicolin B (2); e) ESI ${ }^{-}$HRMS of arenicolin A (1); f) ESIHRMS of arenicolin B (2); g) Fragment ions observed in ESI--MS for arenicolins A (and B). 


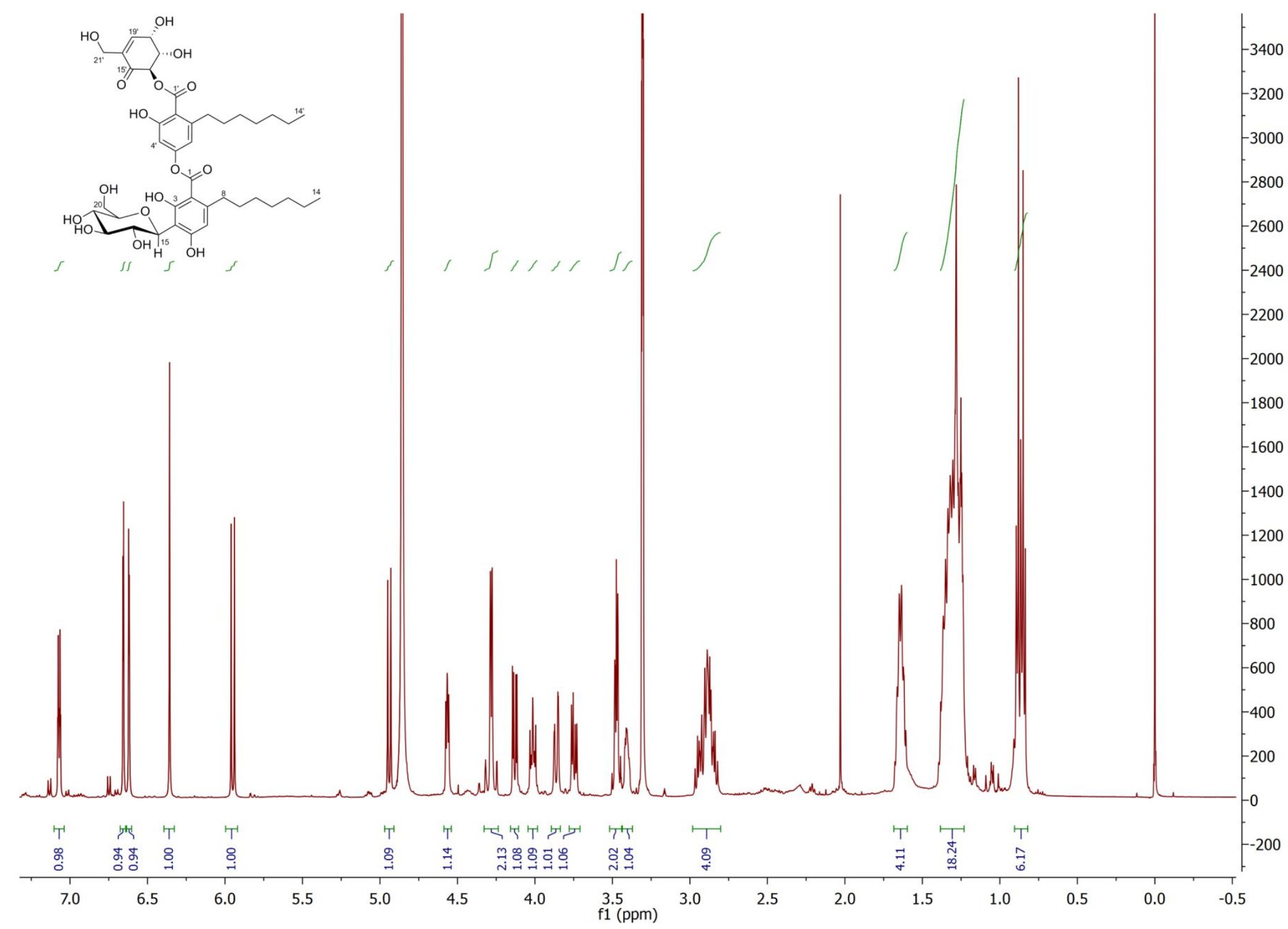

Figure S2. ${ }^{1} \mathrm{H}$ NMR spectrum of arenicolin A (1) in $\mathrm{CD}_{3} \mathrm{OD} .(500 \mathrm{MHz})$ 


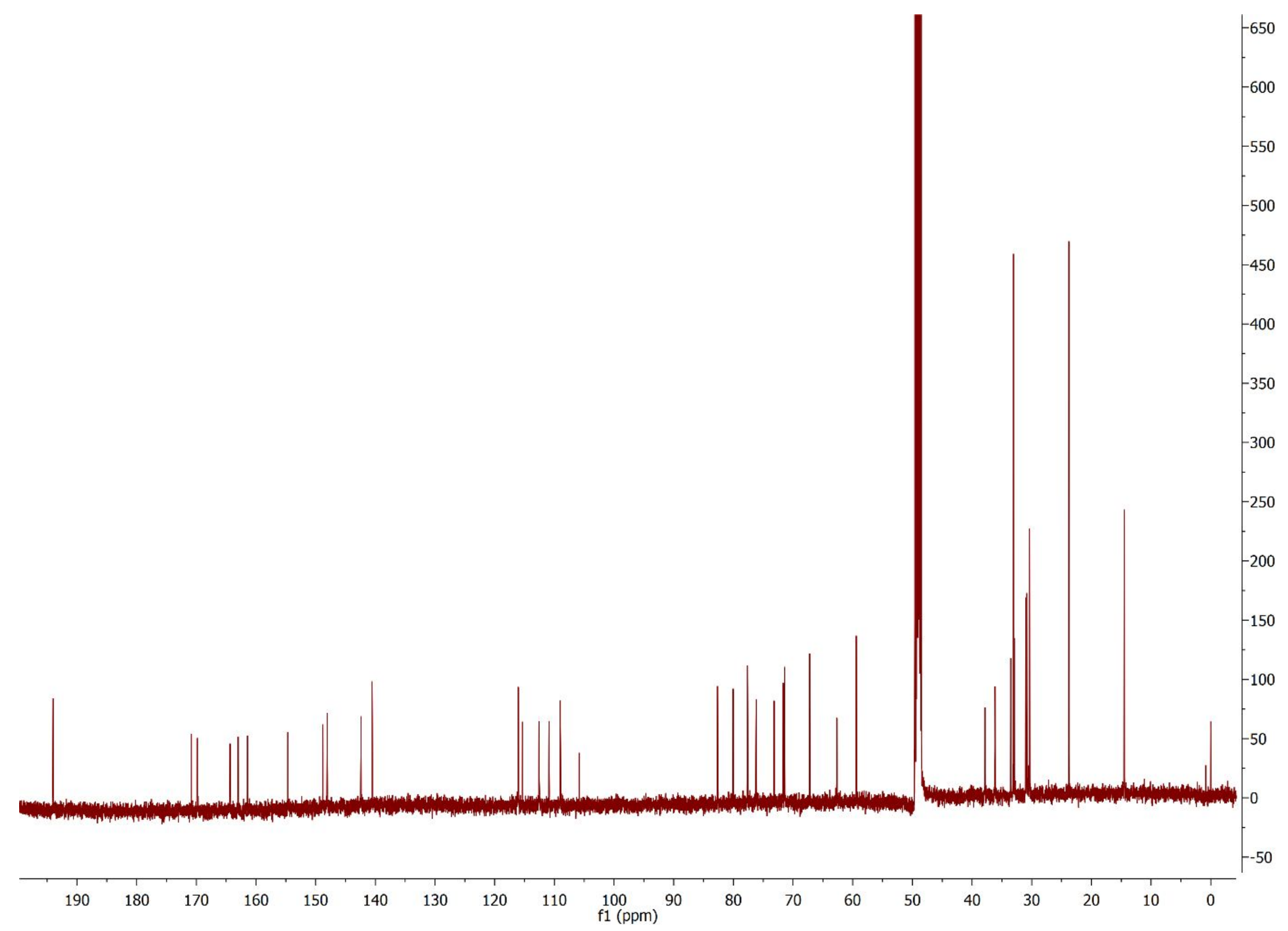

Figure S3. ${ }^{13} \mathrm{C}$ NMR spectrum of arenicolin $\mathrm{A}(\mathbf{1})$ in $\mathrm{CD}_{3} \mathrm{OD} .(125 \mathrm{MHz})$ 


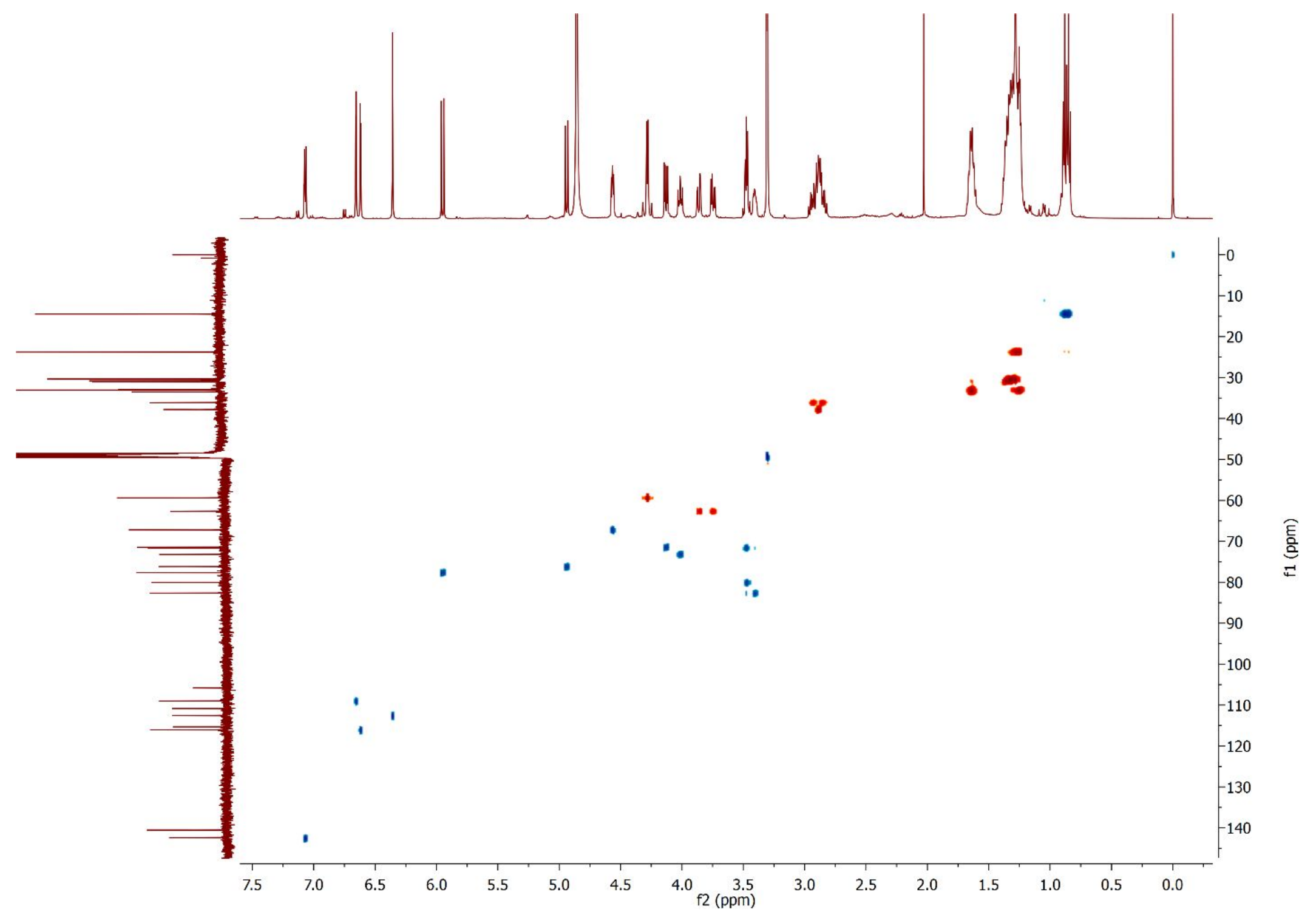

Figure S4. $\mathrm{HSQC}$ spectrum of arenicolin $\mathrm{A}(\mathbf{1})$ in $\mathrm{CD}_{3} \mathrm{OD}$. 


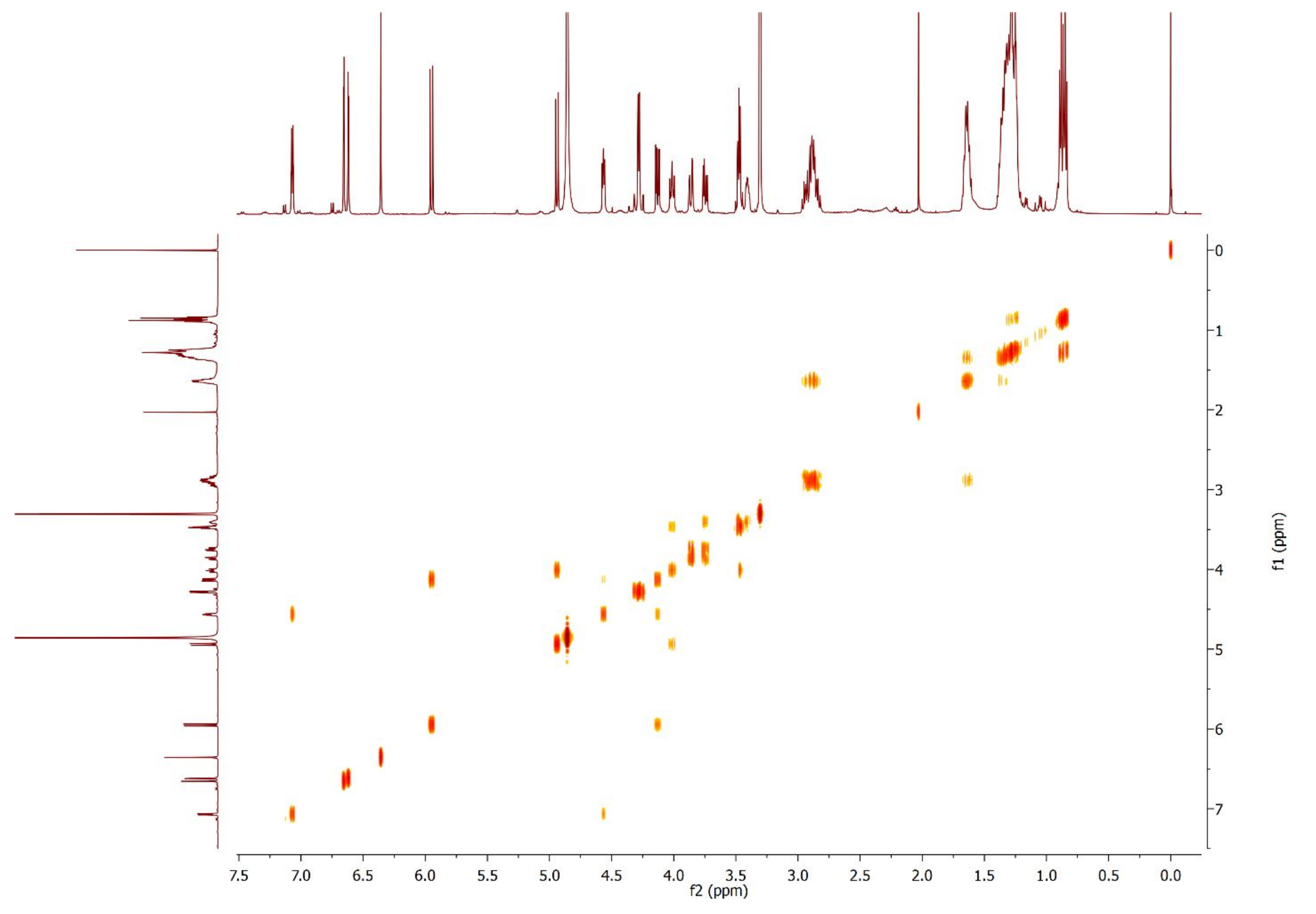

Figure S5. COSY spectrum of arenicolin A (1) in $\mathrm{CD}_{3} \mathrm{OD}$. 


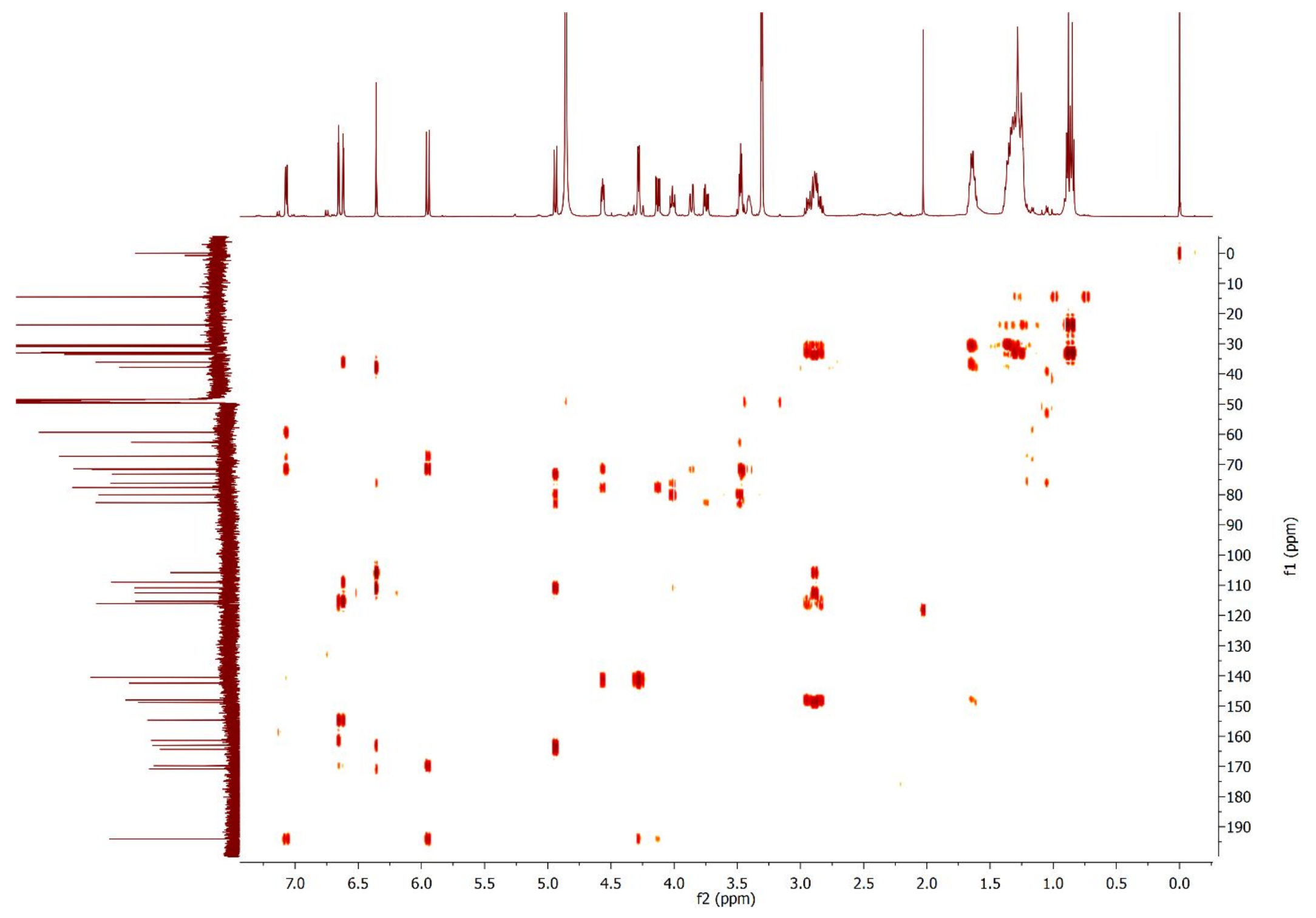

Figure S6. $\mathrm{HMBC}$ spectrum of arenicolin $\mathrm{A}(\mathbf{1})$ in $\mathrm{CD}_{3} \mathrm{OD}$. 


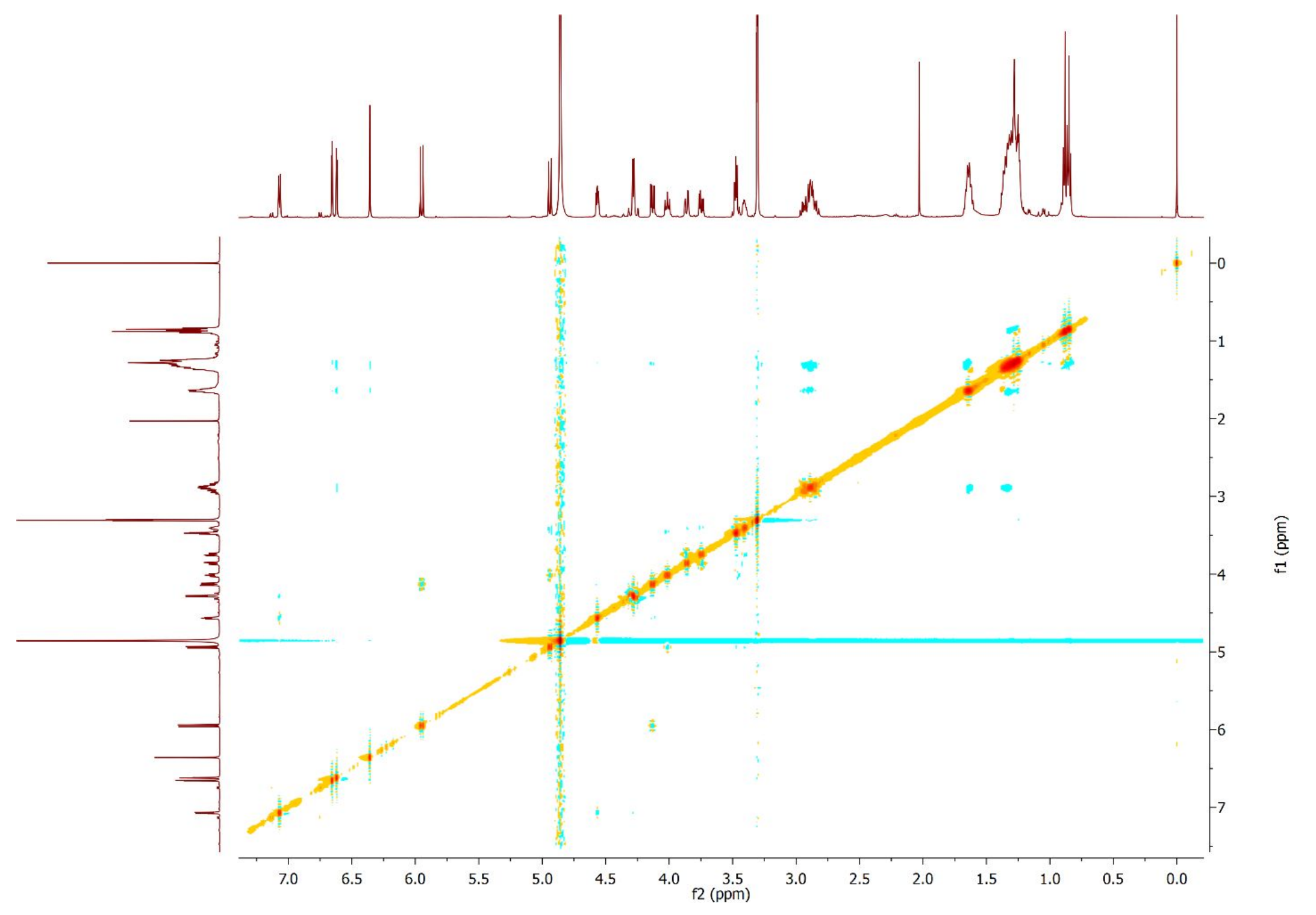

Figure S7. NOESY spectrum of arenicolin $\mathrm{A}(\mathbf{1})$ in $\mathrm{CD}_{3} \mathrm{OD}$. 


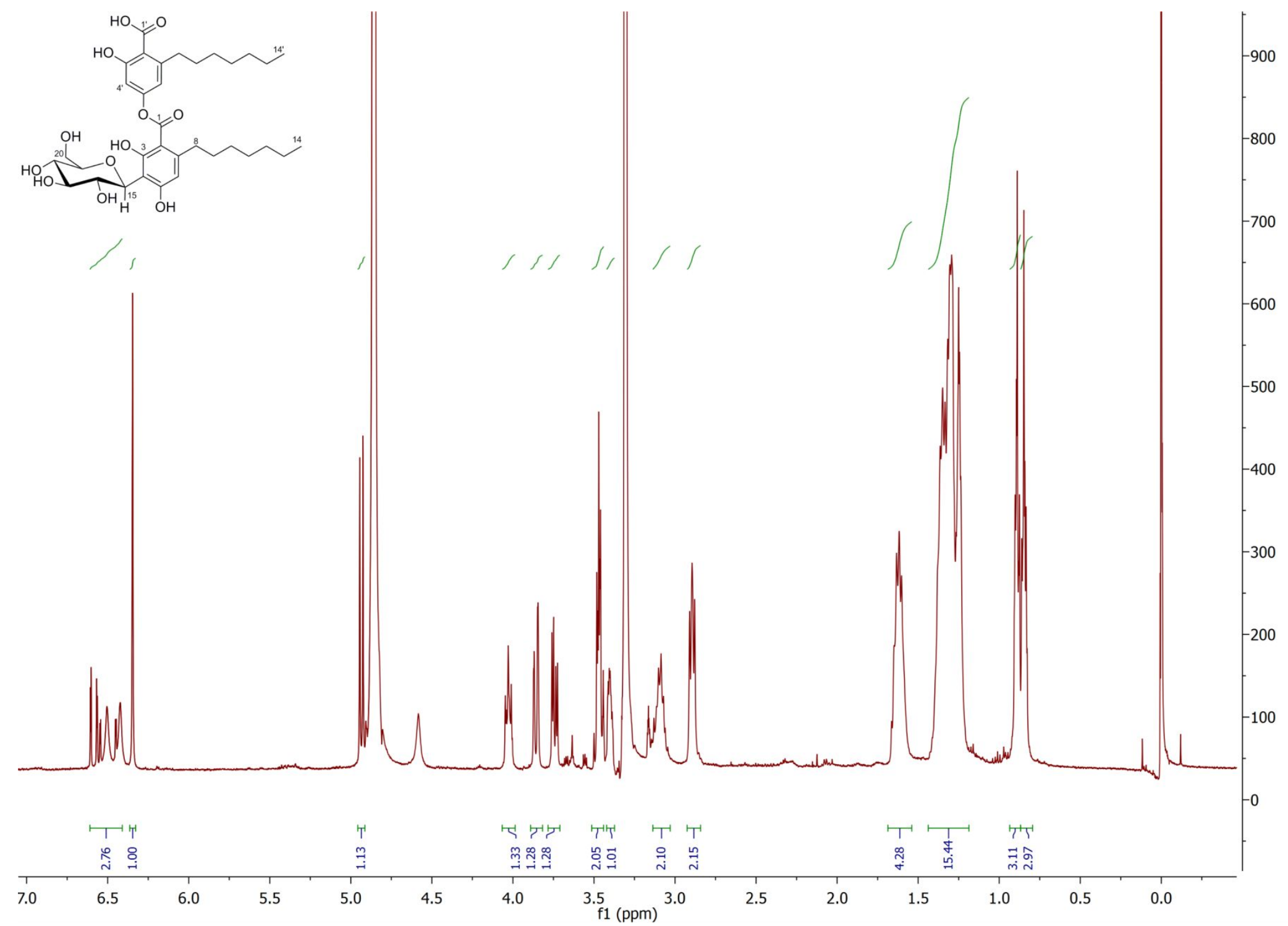

Figure S8. ${ }^{1} \mathrm{H}$ NMR spectrum of arenicolin $\mathrm{B}(2)\left(500 \mathrm{MHz}, \mathrm{CD}_{3} \mathrm{OD}\right)$. 


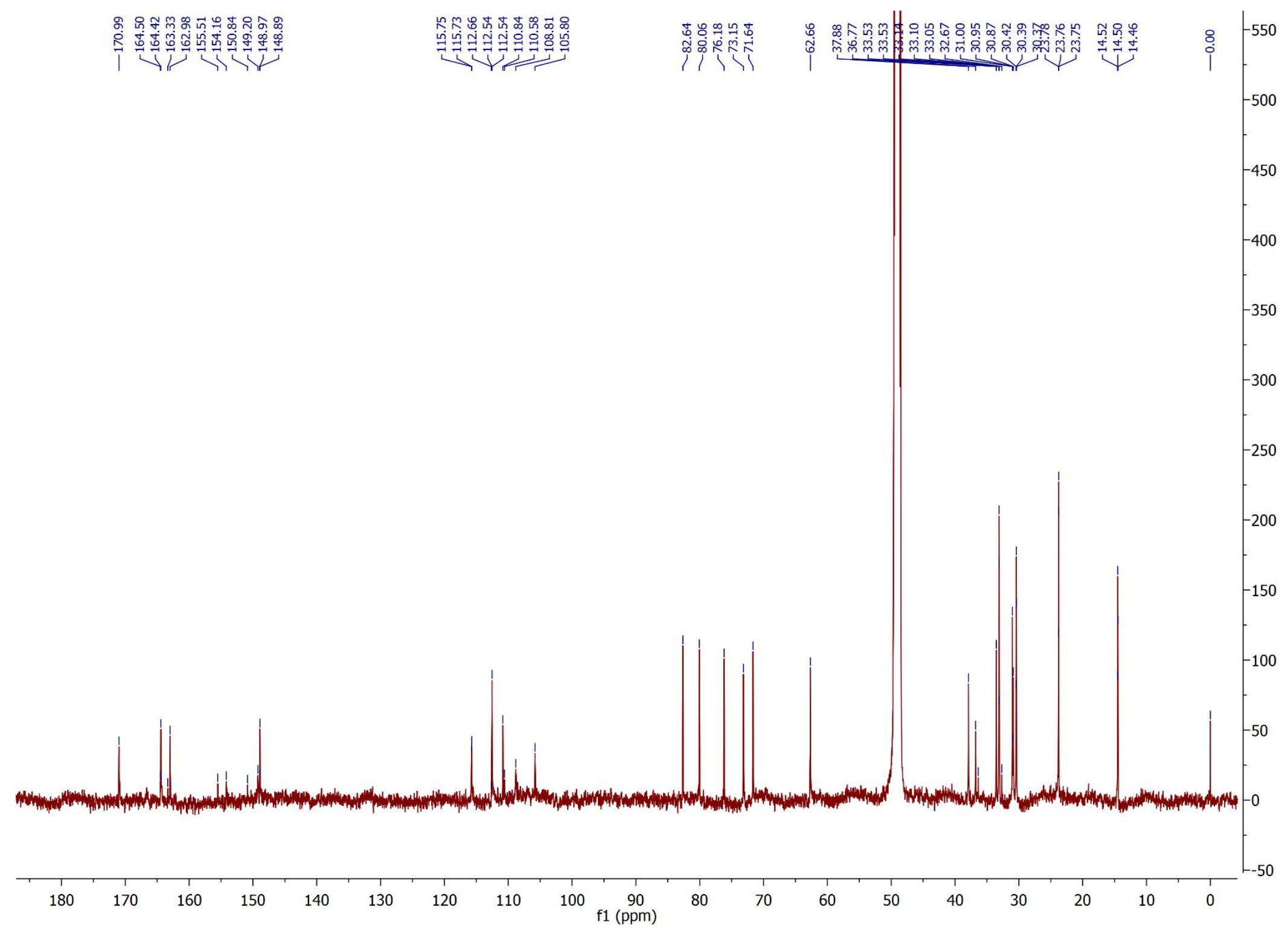

Figure S9. ${ }^{13} \mathrm{C}$ NMR spectrum of arenicolin $\mathrm{B}(2)\left(125 \mathrm{MHz}, \mathrm{CD}_{3} \mathrm{OD}\right)$. 


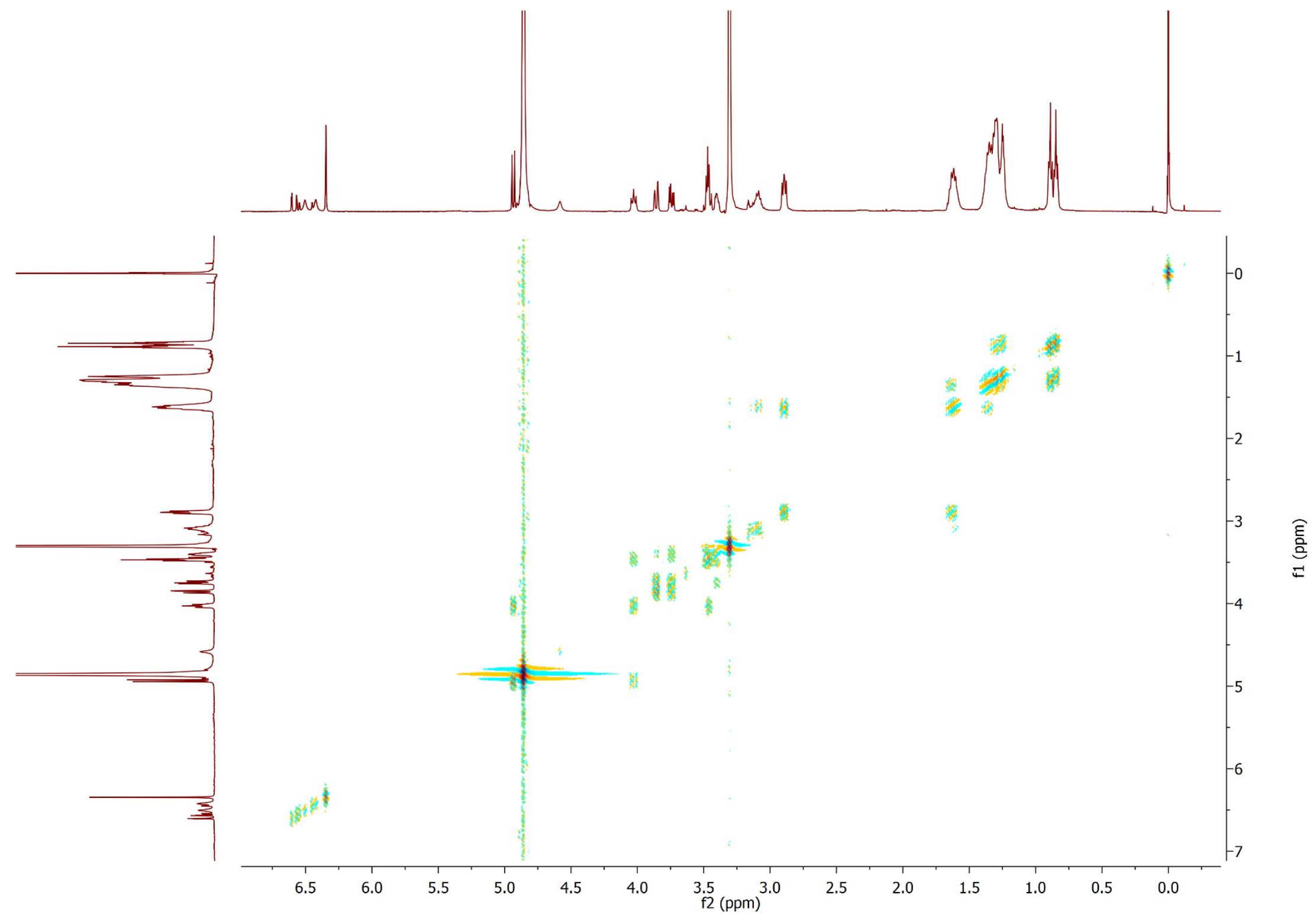

Figure S10. COSY spectrum of arenicolin B (2) in $\mathrm{CD}_{3} \mathrm{OD}$. 


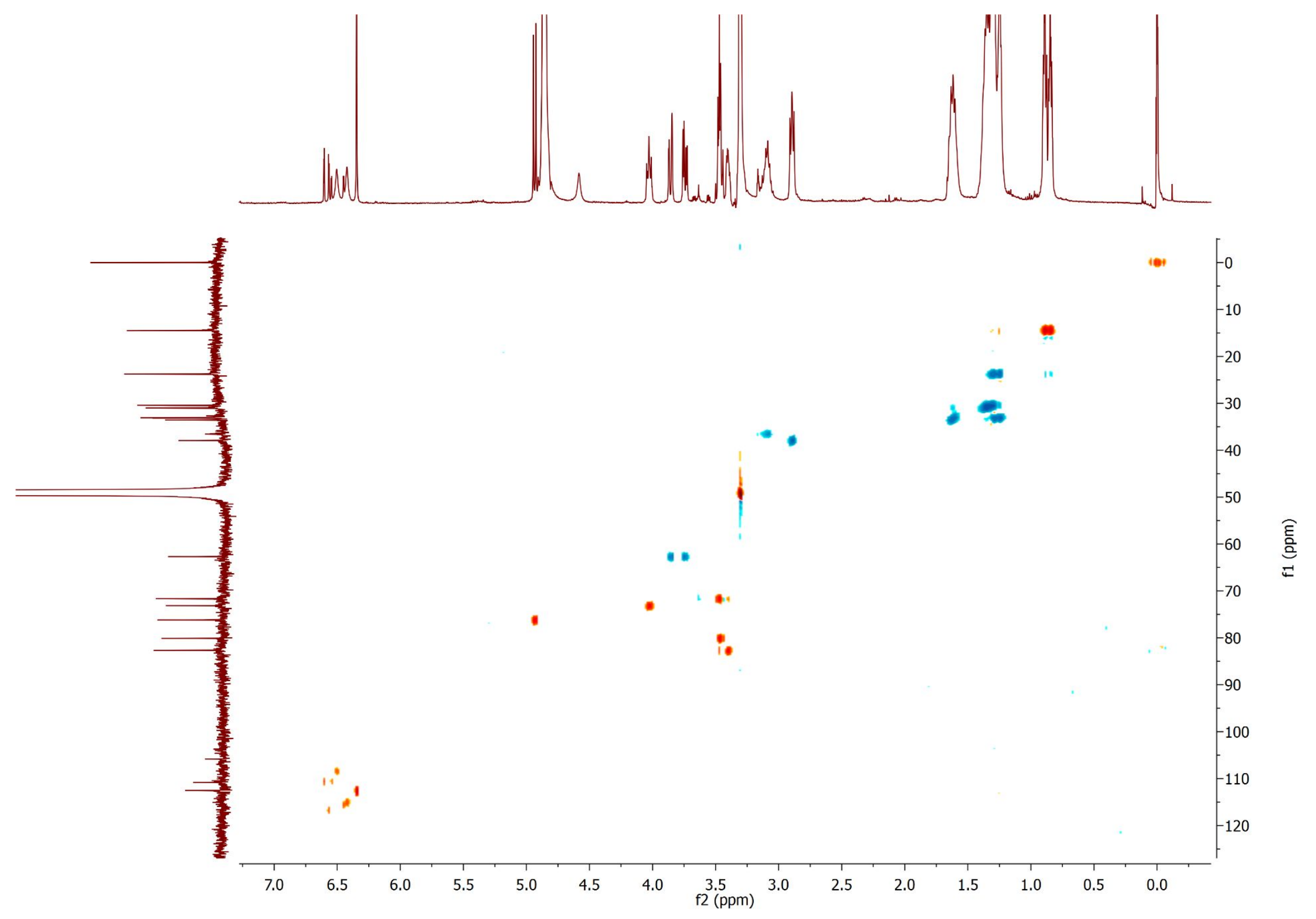

Figure S11. HSQC spectrum of arenicolin B (2) in $\mathrm{CD}_{3} \mathrm{OD}$. 


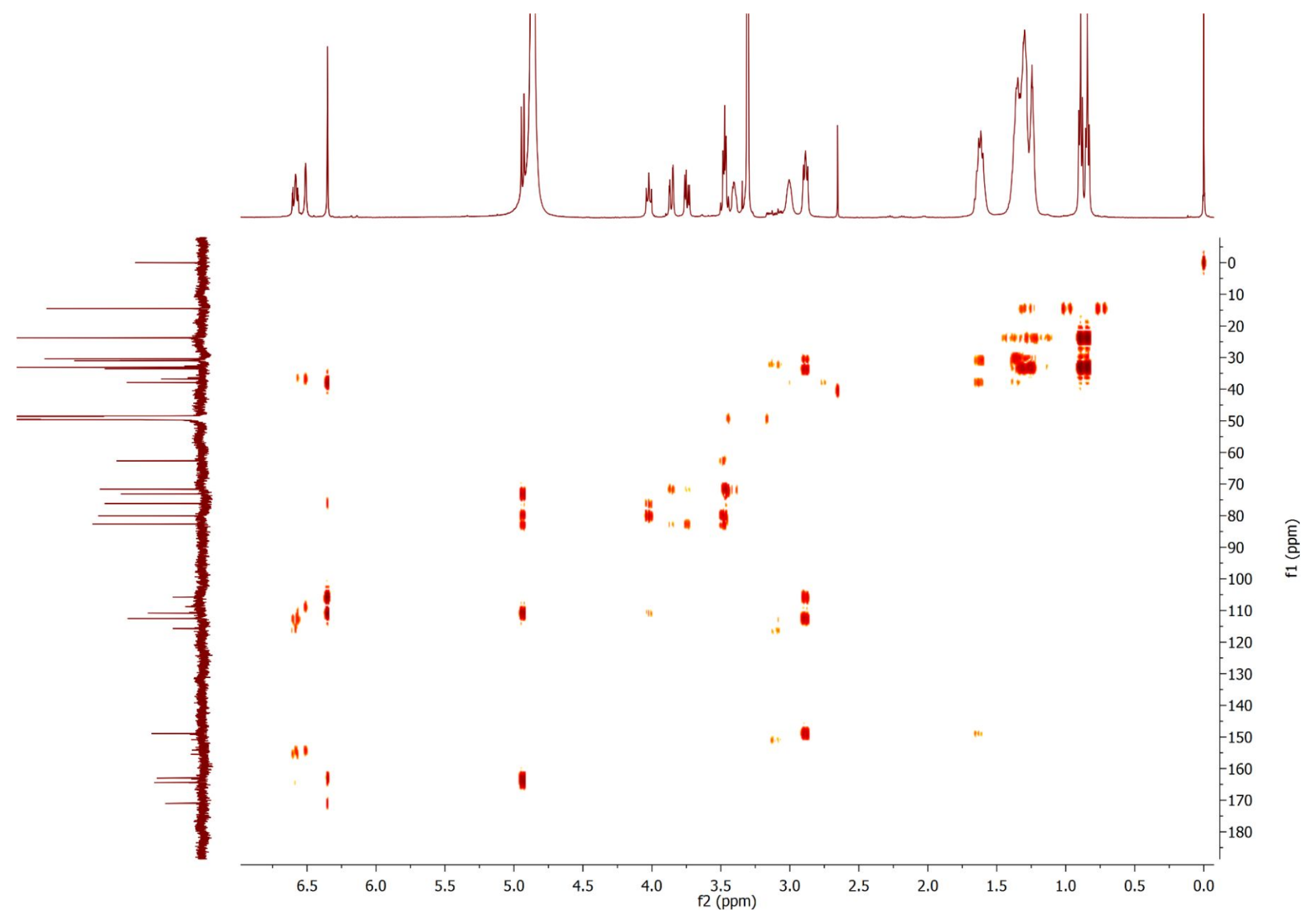

Figure S12. HMBC spectrum of arenicolin $\mathrm{B}(2)$ in $\mathrm{CD}_{3} \mathrm{OD}$ **

*A more concentrated sample was used for this experiment, so the downfield signals appeared differently; see Figure S14 for expansions. 


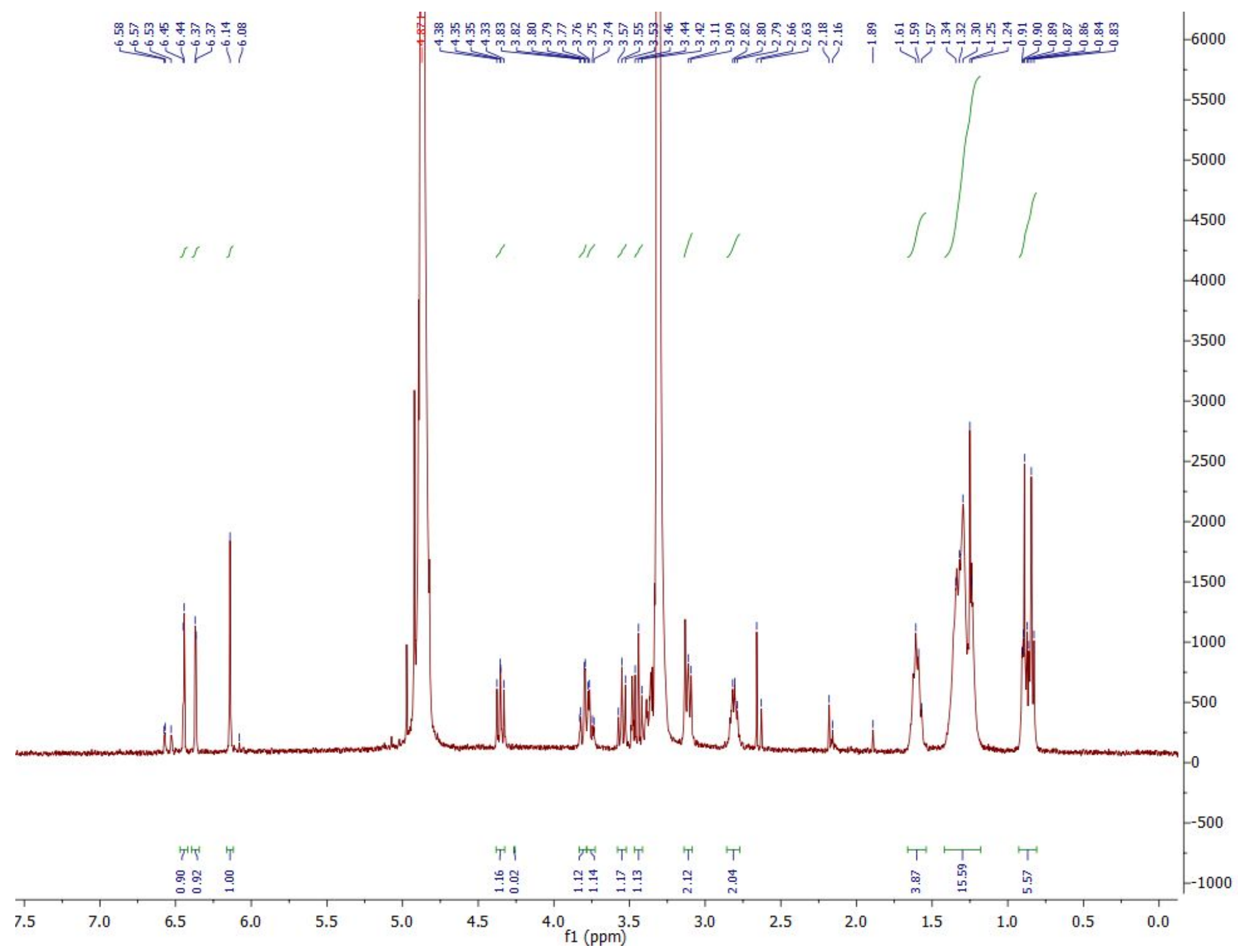

Figure S13. ${ }^{1} \mathrm{H}$ NMR spectrum of arenicolin $\mathrm{B}(2)$ in $\mathrm{CD}_{3} \mathrm{OD} / \mathrm{Na}_{2} \mathrm{CO}_{3}(500 \mathrm{MHz})$ 
Initial spectrum in $\mathrm{CD}_{3} \mathrm{OD}$

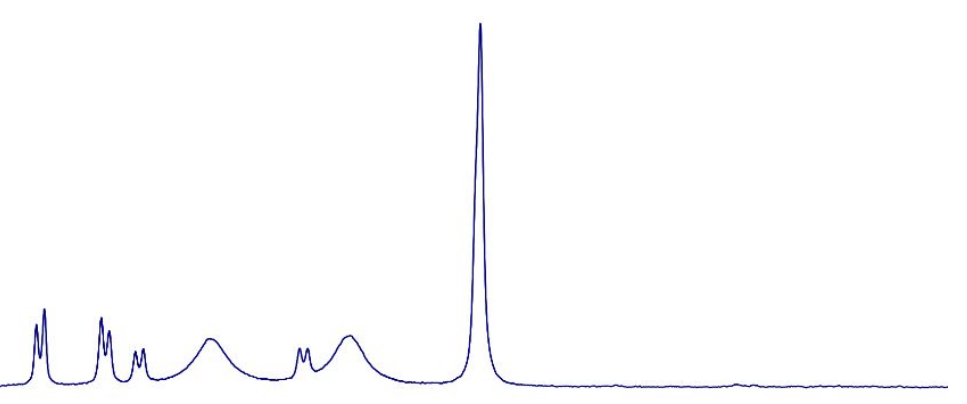

Spectrum in $\mathrm{CD}_{3} \mathrm{OD}$ at higher concentration

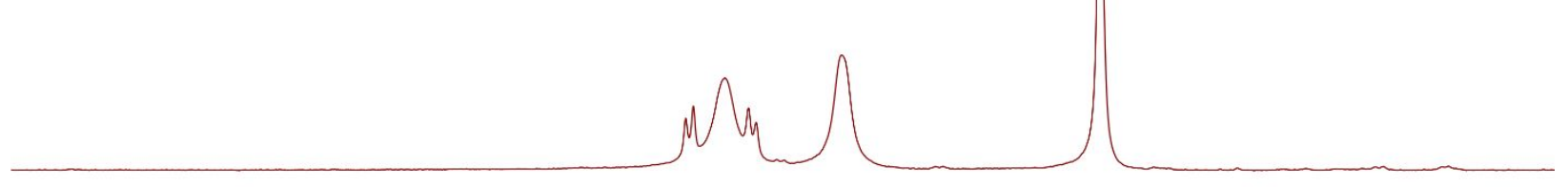

Spectrum in $\mathrm{CD}_{3} \mathrm{OD} / \mathrm{Na}_{2} \mathrm{CO}_{3}$

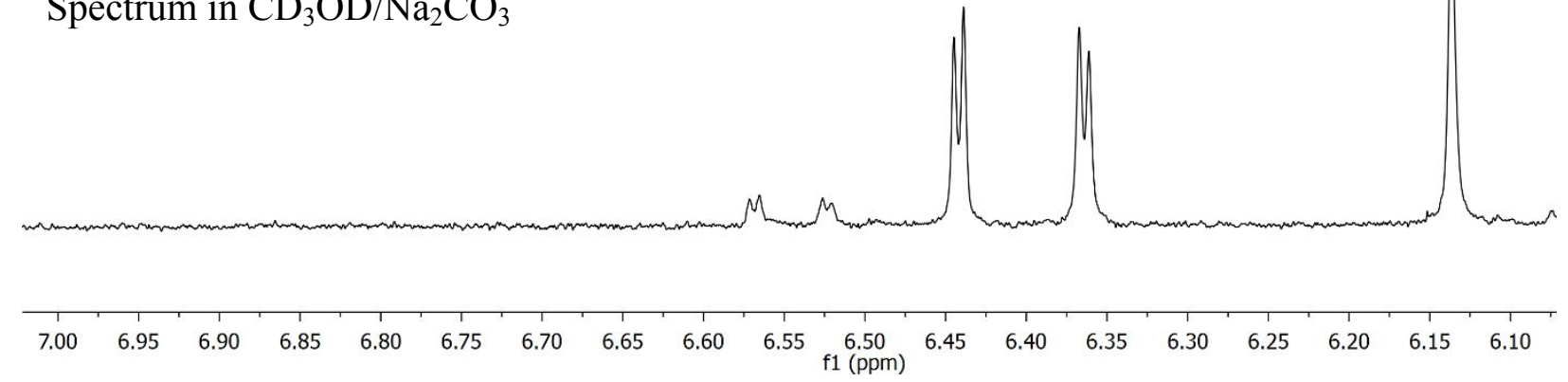

Figure S14. Aromatic region of the ${ }^{1} \mathrm{H}$ NMR spectrum of arenicolin B (2) under different conditions. 


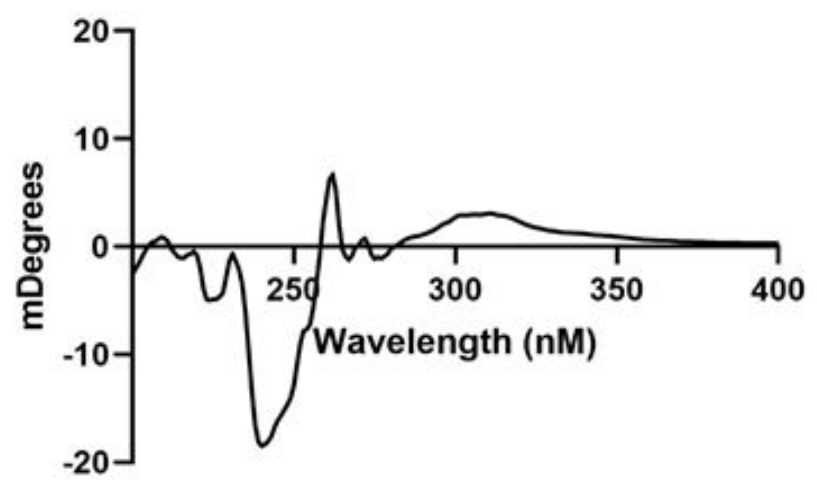

Figure S15. ECD spectrum of arenicolin A (1) in $\mathrm{MeOH}$.

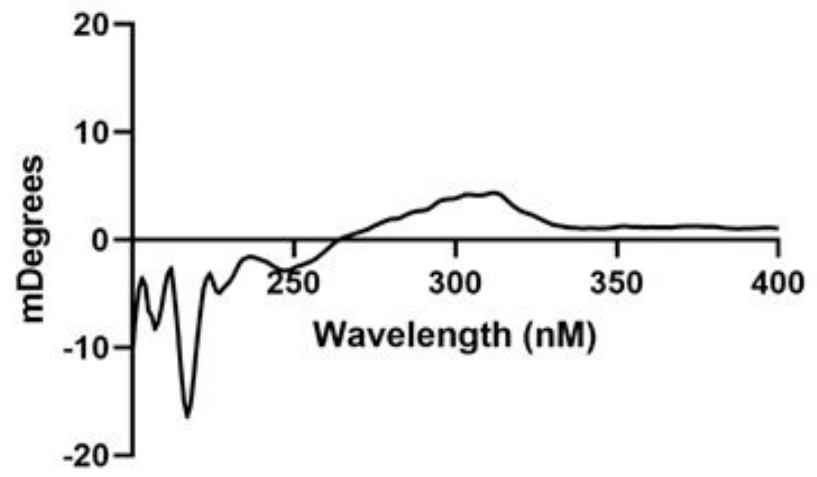

Figure S16. ECD spectrum of arenicolin B (2) in $\mathrm{MeOH}$. 